\title{
Reslizumab in the management of poorly controlled asthma: the data so far
}

This article was published in the following Dove Press journal:

Journal of Asthma and Allergy

31 August 2016

Number of times this article has been viewed

\section{Diego Jose Maselli' \\ Maria Ines Velez' \\ Linda Rogers ${ }^{2}$}

'Department of Medicine, Division of Pulmonary Diseases and Critical Care, University of Texas Health Science Center at San Antonio, San Antonio, TX, ${ }^{2}$ Pulmonary, Critical Care, and Sleep Division, Mount Sinai-National Jewish Health Respiratory Institute, Icahn School of Medicine at Mount Sinai, New York, NY, USA
Correspondence: Diego Jose Maselli Department of Medicine, Division of Pulmonary Diseases and Critical Care, University of Texas Health Science Center at San Antonio, 7400 Mentor Minter MC IIIE, San Antonio, TX 78229, USA

$\mathrm{Tel}+\mathrm{I} 2106175256$

Fax + I 2109493006

Email masellicacer@uthscsa.edu
Abstract: Interleukin-5, an important cytokine in the pathophysiology of asthma, participates in terminal maturation and increases chemotaxis, endothelial adhesion, and activation of eosinophils. Blockade of interleukin-5 activity with monoclonal antibodies have been successful in decreasing eosinophil counts. Reslizumab, a monoclonal antibody that targets interleukin-5, has been studied for the treatment of severe asthma. Several studies have shown that reslizumab can effectively treat severe asthma with an eosinophilic phenotype. Compared to placebo, patients treated with reslizumab had a reduction in the rates of asthma exacerbations and experienced improvement in $\mathrm{FEV}_{1}$ and asthma control questionnaires scores as early as 4 weeks after the therapy was initiated. Reslizumab was not effective in various asthma outcomes in patients without eosinophilia. The adverse events reported were similar in both treatment and placebo groups. Patients should be observed immediately after treatment because anaphylaxis may occur rarely $(0.3 \%)$ after exposure to reslizumab. Future surveillance studies are still needed to establish the risks of malignancy and safety during pregnancy.

Keywords: Sch 55700, reslizumab, anti-IL-5, IL-5 blockage, IL-5 antibody, severe asthma, eosinophilic asthma

\section{Introduction}

Over the past 2 decades, there has been a considerable increase in the interest of targeted therapies for asthma. With the development of monoclonal antibodies that neutralize specific cytokines and the aid of biomarkers, new avenues for the treatment of asthma have been explored. Monoclonal antibodies such as omalizumab, which targets immunoglobulin $\mathrm{E}$, have been used effectively in treating patients with allergic asthma with sensitivity to perennial allergens uncontrolled with inhaled corticosteroids (ICSs) with or without another controller. ${ }^{1}$ Nevertheless, there remains a significant population of patients with severe asthma not controlled with current therapies, including omalizumab, and thus additional therapies are still needed.

One such therapy is reslizumab, a monoclonal antibody that inhibits interleukin-5 (IL-5). IL-5 has a major role in the maturation and activation of eosinophils, cells that play a pivotal role in the pathophysiology of asthma and figure prominently in type 2 inflammatory response. Recently, the Federal Drug Administration (FDA) approved reslizumab as an add-on maintenance therapy for adults with severe asthma with an eosinophilic phenotype.

Here, we review the evidence to date on the efficacy and safety of reslizumab in eosinophilic asthma. We also discuss other anti-IL-5 therapies and their role in treatment 
of severe asthma. Lastly, we conclude with some thoughts of where anti-IL-5 agents fit at this time in clinical practice and future clinical questions regarding the role of these therapies. For this review, trials and reports were identified from the databases of PubMed/Medline and ClinicalTrials.gov from the US National Institutes of Health and the Cochrane Register of Controlled Trials. The search was carried out using the keywords "Sch 55700" or "reslizumab" or "anti-IL-5" or "IL-5 blockage" or "IL-5 antibody with asthma". No date or language restrictions were used.

\section{IL-5 and eosinophils}

It has been known now for decades that eosinophils play a central role in the pathophysiology of many patients with asthma. ${ }^{2}$ When activated, eosinophils release leukotrienes, platelet activation factor, major basic protein, eosinophil cationic protein, eosinophil peroxidase, eosinophil-derived neurotoxin, and other cytokines that are cytotoxic to the bronchial epithelium and lead to airway inflammation and bronchospasm..$^{3-6}$

Until recently, it was thought that IL-5 was produced mainly by TH2 lymphocytes, although eosinophils, mast cells, and other cellular lines produce this cytokine at varying degrees. ${ }^{7-9}$ The production of IL-5 is increased upon activation of TH2 cells after antigen exposure. IL-5 stimulates the production and maturation of eosinophil precursors in the bone marrow. Peripherally, it participates in terminal maturation and activation of eosinophils. In addition, it has a role in diapedesis of eosinophils by facilitating endothelial adhesion and chemotaxis. ${ }^{10}$ Integrins, a type of cellular adhesion receptors, play a major role in eosinophilic migration. ${ }^{11,12}$ Studies have shown that increased surface densities of integrins in eosinophils are correlated with IL-5 concentrations in bronchoalveolar lavage fluid, and eosinophils present in IL-5-rich airway fluid exhibit hyperadhesive characteristics. ${ }^{13}$ These findings have been supported by experiments in which blockade of IL-5 by a monoclonal antibody resulted in decreased surface densities of integrins in eosinophils. ${ }^{14}$

Recently, a subset of innate lymphoid cells (a family of lymphocytes separate from T- and B-cells) that produce type 2 cytokines have been identified in mice and humans, including the airways of humans with severe asthma. ${ }^{15}$ In mice, these cells lack specific antigen receptors of $\mathrm{TH} 2$ cells but are important sources of IL-5 and may have a key role in the initiation and maintenance of the type 2 inflammatory response. ${ }^{16}$ Blockade of IL-5 activity with subsequent reduction in the production and activation of eosinophils is an attractive modality to treat allergic asthma as well as nonallergic forms of asthma where eosinophilia is prominent.

\section{Reslizumab}

Reslizumab (previously Sch 55700) is a humanized monoclonal antibody that targets IL-5. ${ }^{17}$ It occupies the region ERRR (glutamic acid, arginine, arginine, arginine) corresponding to amino acids 89-92 on IL-5, which is critical for its interaction with the receptor with subsequent inhibition of IL-5 bioactivity. ${ }^{18}$ Early animal models showed promise with appropriate inhibition of eosinophilic-driven inflammation. For example, Egan et a ${ }^{19}$ were able to show a significant reduction in eosinophil counts in monkeys, mice, and guinea pigs on allergic experimental models after a single dose of reslizumab. Importantly, in these experiments, the effects appeared to last at least 6 months. ${ }^{19,20}$

\section{Clinical use}

Reslizumab was initially evaluated in humans in a small study that enrolled patients, 18 years or older, with symptomatic severe persistent asthma despite using high-dose ICSs or oral corticosteroids. ${ }^{21}$ The patients $(n=32)$ received either placebo or reslizumab intravenously (IV) at a single dose raging between 0.03 and $1.0 \mathrm{mg} / \mathrm{kg}$. At doses of 0.03 and $0.1 \mathrm{mg} / \mathrm{kg}$, there was no significant effect on eosinophil counts. At doses of $0.3 \mathrm{mg} / \mathrm{kg}$, there was a modest decrease in circulating eosinophils, but in patients who received 1.0 $\mathrm{mg} / \mathrm{kg}$, the response was more profound. Importantly, in the last group of patients, the effect was sustained for 30 days. There were no significant differences in forced expiratory volume in 1 second $\left(\mathrm{FEV}_{1}\right), \mathrm{FEV}_{1} /$ forced vital capacity ratio, or symptom scores among the study groups. This study has important implications as it was the first to demonstrate that reslizumab can effectively and safely decrease eosinophil counts in patients with asthma. Clinical outcomes were disappointing, but this was likely due to the characteristics of the study: 1) not powered to detect a difference, 2) lack of repeat dosing, 3) insufficient follow-up, and 4) no preselection of patients with eosinophilia.

Indeed, adequate preselection of patients with eosinophilia has been the focus of subsequent reslizumab studies (Table 1). A multicenter, randomized, double-blind, placebocontrolled study explored the effects of reslizumab versus placebo in poorly controlled asthmatics aged 18-75 years with 1) confirmed airway reactivity, 2) receiving high-dose ICS in addition to a second controller, and 3) induced sputum eosinophils of $3 \%$ or more. ${ }^{22}$ Patients received reslizumab 
Table I Studies of reslizumab in asthma

\begin{tabular}{|c|c|c|c|c|c|}
\hline Study & Study design & $\begin{array}{l}\text { Number of } \\
\text { patients }\end{array}$ & Population & Regimen & Main findings \\
\hline Kips et $\mathrm{al}^{21}$ & $\begin{array}{l}\text { Randomized, double } \\
\text { blind }\end{array}$ & 32 & $\begin{array}{l}\text { Symptomatic severe persistent } \\
\text { asthmatics despite using high-dose } \\
\text { inhaled or oral corticosteroids }\end{array}$ & $\begin{array}{l}\text { Single dose of } \\
\text { reslizumab IV at } \\
\text { doses ranging from } \\
0.03 \text { to } 1.0 \mathrm{mg} / \mathrm{kg} \text { or } \\
\text { placebo }\end{array}$ & $\begin{array}{l}\text { No biological activity seen at } \\
\text { doses below } 0.03 \mathrm{mg} / \mathrm{kg} \text {. Dose of } \\
1.0 \mathrm{mg} / \mathrm{kg} \text { produced a significant } \\
\text { reduction in eosinophil counts. No } \\
\text { improvement in pulmonary function } \\
\text { or symptom scores }\end{array}$ \\
\hline Castro et $\mathrm{al}^{22}$ & $\begin{array}{l}\text { Multicenter, } \\
\text { randomized, double } \\
\text { blind, placebo } \\
\text { controlled }\end{array}$ & 106 & $\begin{array}{l}\text { Poorly controlled asthmatics with } \\
\text { airway reactivity, on high-dose } \\
\text { ICS+ to a second controller, and } \\
\text { sputum eosinophils } \geq 3 \%\end{array}$ & $\begin{array}{l}\text { Reslizumab } 3.0 \mathrm{mg} / \\
\mathrm{kg} \text { IV or placebo } \\
\text { at baseline and at } \\
\text { weeks } 4,8 \text {, and } 12\end{array}$ & $\begin{array}{l}\text { A trend toward improved } \mathrm{ACQ} \\
\text { scores, with patients with nasal } \\
\text { polyps with a more substantial } \\
\text { response. A trend toward } \\
\text { improvement in exacerbation rates } \\
\text { (8\% vs } 19 \%) \text {. Eosinophils significantly } \\
\text { decreased in sputum }\end{array}$ \\
\hline Castro et $\mathrm{al}^{26}$ & $\begin{array}{l}\text { Two replicate } \\
\text { trials, multicenter, } \\
\text { randomized, double } \\
\text { blind, placebo } \\
\text { controlled }\end{array}$ & 953 & $\begin{array}{l}\text { Poorly controlled asthmatics } \\
\text { despite using at least medium-dose } \\
\text { ICS with or without a controller } \\
\text { and a blood eosinophil count of } \\
\geq 400 \text { cells per } \mu \mathrm{L}\end{array}$ & $\begin{array}{l}\text { Reslizumab } 3 \mathrm{mg} / \mathrm{kg} \\
\text { IV or placebo every } \\
4 \text { weeks } \times 13 \text { doses }\end{array}$ & $\begin{array}{l}\text { Reduction in rates of asthma } \\
\text { exacerbations and improvement in } \\
\mathrm{FEV} \text {, and asthma control }\end{array}$ \\
\hline Corren et $\mathrm{al}^{27}$ & $\begin{array}{l}\text { Multicenter, } \\
\text { randomized, double } \\
\text { blind, placebo } \\
\text { controlled }\end{array}$ & 496 & $\begin{array}{l}\text { Poorly controlled asthmatics } \\
\text { despite using at least medium-dose } \\
\text { ICS with or without a controller } \\
\text { without preselection eosinophil } \\
\text { count criteria }\end{array}$ & $\begin{array}{l}\text { Reslizumab } 3.0 \text { mg/ } \\
\text { kg IV or placebo } \\
\text { every } 4 \text { weeks } \times 4 \\
\text { doses }\end{array}$ & $\begin{array}{l}\text { No difference in } \mathrm{FEV}_{1} \text { in both study } \\
\text { groups. Subgroup analysis in subjects } \\
\text { with blood eosinophil count of } \geq 400 \\
\text { cells per } \mu \mathrm{L} \text { had improvements } \\
\text { in } \mathrm{FEV}_{1}, \mathrm{ACQ} \text { scores, and rescue } \\
\text { inhaler use }\end{array}$ \\
\hline Bjermer et $\mathrm{al}^{28}$ & $\begin{array}{l}\text { Multicenter, } \\
\text { randomized, double } \\
\text { blind, placebo } \\
\text { controlled }\end{array}$ & 315 & $\begin{array}{l}\text { Poorly controlled asthmatics } \\
\text { despite using at least medium-dose } \\
\text { ICS with or without a controller } \\
\text { and a blood eosinophil count of } \\
\geq 400 \text { cells per } \mu \mathrm{L}\end{array}$ & $\begin{array}{l}\text { Reslizumab } 0.3 \text { or } \\
3.0 \mathrm{mg} / \mathrm{kg} \text { IV or } \\
\text { placebo every } 4 \\
\text { weeks } \times 4 \text { doses }\end{array}$ & $\begin{array}{l}\text { The } 3.0 \mathrm{mg} / \mathrm{kg} \text { dose had } \\
\text { improvement in pulmonary function } \\
\text { and self-reported asthma control } \\
\text { and quality of life }\end{array}$ \\
\hline
\end{tabular}

Abbreviations: ACQ, asthma control questionnaire; $\mathrm{FEV}_{1}$, forced expiratory volume in I second; ICS, inhaled corticosteroids; IV, intravenous.

infusions at a dose of $3.0 \mathrm{mg} / \mathrm{kg}$ or placebo at baseline and every 4 weeks for three additional doses. The primary outcome - Asthma Control Questionnaire (ACQ) scores - showed a trend favoring better asthma control in the reslizumab group $(-0.7$ vs -0.3$)$, but was not considered statistically significant $(P=0.054)$. Subgroup analysis revealed that patients with nasal polyps had a significant response to reslizumab in the ACQ scores compared to placebo ( -1.0 vs $-0.1, P=0.012$ ). There was also a trend toward improvement in the exacerbation rates in the reslizumab group compared to placebo: $8 \%$ versus $19 \%$ (0.33 [0.10, 1.15], $P=0.083)$ of the patients had at least one exacerbation, respectively. Additionally, when analyzing the whole cohort, there was a modest improvement from baseline in $\mathrm{FEV}_{1}$ in the reslizumab group compared to placebo (180 vs $-80 \mathrm{~mL}, P=0.002$ ). Patients who received reslizumab had significant decrease in sputum eosinophils, and the therapy was well tolerated. This study was the first to explore the use of reslizumab in asthmatic patients who were previously categorized into the eosinophilic asthma phenotype. Although the response was modest, it was demonstrated that by targeting this subset of patients, reslizumab was able to improve asthma control and pulmonary function.

In the previously discussed study by Castro et al, ${ }^{22}$ patients were selected on the basis of induced sputum eosinophil counts. This test has limitations as it has been shown to be variable, demands certain expertise when collecting the sample, and is not widely available. ${ }^{23,24}$ For these reasons, sputum eosinophil counts may not be the ideal way of identifying eosinophilic asthma. On the other hand, blood eosinophil counts are readily obtained in an automated, inexpensive fashion and provide more reliable results. ${ }^{25}$ For these reasons, follow-up studies evaluating the effectiveness of reslizumab have used blood eosinophil counts to define the eosinophilic asthma phenotype.

To explore the efficacy of anti-IL-5 therapy using blood eosinophil counts, two replicate, double-blind, multicenter, randomized, placebo-controlled trials evaluated the efficacy of reslizumab in uncontrolled asthmatics. ${ }^{26}$ Importantly, these patients had to have at least one blood eosinophil count of $400 / \mu \mathrm{L}$ and were receiving at least medium-dose ICS with or without 
a second controller. After screening, 953 patients aged 12-75 years were randomly assigned to receive reslizumab at a dose of $3 \mathrm{mg} / \mathrm{kg}$ or placebo IV every 4 weeks for 13 doses. Majority of the patients (ie, 84\%) were receiving long-acting $\beta$-agonists. Patients who received reslizumab had a reduction in the rates of asthma exacerbations compared to placebo ( 0.84 vs 1.81 events per patient per year, rate ratio $0.86[0.37-0.58], P<0.001)$. The time to first exacerbation was significantly longer in the treatment group, with a probability of not having an exacerbation of $61 \%$ and $73 \%$ (95\% confidence interval 55-67, 67-79) in studies 1 and 2 compared to $44 \%$ and 52\% (95\% confidence interval 38-51, 45-48) in the placebo group, respectively. Larger reductions in exacerbation rates were noted in patients with repeated exacerbations in the period of 12 months before the trial. Patients in the treatment group also experienced improvement in $\mathrm{FEV}_{1}$ and $\mathrm{ACQ}$ s scores as early as 4 weeks after therapy was initiated. The adverse events reported were similar in both treatment and placebo groups. The results were promising and further provide evidence that blood eosinophil counts are suitable to discriminate different asthma phenotypes.

To determine the impact of the baseline blood eosinophil count, a randomized, double-blind, placebo-controlled, multicenter study was designed to evaluate the use of reslizumab in uncontrolled asthmatics with a wide range of blood eosinophil levels. ${ }^{27}$ As with the previous studies, patients had to be at least on medium-dose ICS with or without a second controller. A total of 496 patients aged 18-65 years were randomized (4:1) to receive either reslizumab at a dose of $3.0 \mathrm{mg} / \mathrm{kg}$ IV every 4 weeks for 16 weeks or placebo. Only $20 \%$ of the patients had blood eosinophil counts $>400 / \mu \mathrm{L}$. The mean change in $\mathrm{FEV}_{1}$ from baseline at week 16 was similar in both the study groups (reslizumab $255 \mathrm{~mL}$ compared to placebo $187 \mathrm{~mL}$, standard error 49.5, $P=0.170$ ). Subgroup analysis in subjects with eosinophil counts $>400 / \mu \mathrm{L}$ revealed an improvement in pulmonary function, ACQ scores, and rescue inhaler use. This study confirmed that asthmatics without eosinophilia do not benefit from reslizumab therapy.

More recently, a study was carried out to explore the efficacy of two different doses $(0.3$ and $3.0 \mathrm{mg} / \mathrm{kg} \mathrm{IV})$ of reslizumab in asthmatics with a blood eosinophil count of at least $400 / \mu \mathrm{L} .{ }^{28}$ This multicenter, double-blind, placebocontrolled study included 315 subjects aged $12-75$ years with uncontrolled asthma (ACQ score $\geq 1.5$ ) and at least using medium-dose ICS (78\% were using long-acting $\beta$-agonists). After 16 weeks of therapy, patients who received the $3.0 \mathrm{mg} /$ $\mathrm{kg}$ dose had clinically significant improvements in pulmonary function, quality of life, and self-reported asthma control compared to placebo. As with previous studies, the response was observed as early as 4 weeks, and a significant decrease in the blood eosinophil count was appreciated. Even though there was a significant response with the $0.3 \mathrm{mg} / \mathrm{kg}$ dose, the effect was considered superior with the $3.0 \mathrm{mg} / \mathrm{kg}$ dosing scheme. In both the dosing schemes, no increased rates of adverse reactions were observed compared to placebo.

Based on the previous four studies, in March 2016 the FDA concluded that reslizumab had an adequate safety profile and demonstrated efficacy in treating severe eosinophilic asthma. ${ }^{26-28}$ The approved dosage regimen is $3 \mathrm{mg} / \mathrm{kg}$ IV over 20-50 minutes every 4 weeks for patients aged $\geq 18$ years.

\section{Safety}

Reslizumab appears to be safe and is well tolerated. ${ }^{21,22,26-29}$ The most common reported side effects include headache, nasopharyngitis, upper respiratory tract infections, and fatigue, although these occurred at similar rates compared to placebo. Because $0.3 \%$ patients who received reslizumab in the preapproval trials developed anaphylaxis, the FDA issued a warning and recommended that after the infusion patients should be observed in a setting where health care professionals are available to treat this adverse reaction. Future surveillance studies are still needed to establish the risks of malignancy and safety during pregnancy.

\section{Other IL-5 inhibitors for the treatment of asthma Mepolizumab}

Mepolizumab, a humanized monoclonal antibody, inhibits IL-5 activity by preventing the binding of IL-5 to the $\alpha$ chain of the IL-5 receptor. ${ }^{30}$ Early studies demonstrated that mepolizumab was effective in decreasing eosinophil counts, decreasing eosinophil progenitors in the bronchial mucosa, and suppressing the maturation rates in the bone marrow of asthmatics. ${ }^{30,31}$ Subsequent studies demonstrated that mepolizumab was effective in improving various outcomes in eosinophilic asthma. A meta-analysis of seven randomized placebo-controlled trials evaluating the effect of IV mepolizumab revealed a significant reduction in blood and sputum eosinophil counts, risk of exacerbation, and asthma symptoms based on quality of life questionnaires compared to placebo. ${ }^{32}$ Notably, the safety profile of mepolizumab in these trials was similar to that in placebo. Two additional trials were done to evaluate the efficacy of mepolizumab using subcutaneous (SC) dosing. The Mepolizumab as Adjunctive Therapy in Patients with Severe Asthma (MENSA) study was a randomized, double-blind, double-dummy trial that evaluated the efficacy of mepolizumab at a dose of $75 \mathrm{mg}$ 
IV or $100 \mathrm{mg}$ SC or placebo every 4 weeks for 32 weeks in asthmatics aged $12-82$ years. ${ }^{33}$ The subjects $(n=576)$ had the clinical diagnosis of asthma, evidence of obstruction on spirometry, confirmed airway reactivity, evidence of eosinophilic inflammation, and at least two asthma exacerbations in the previous year. The patients were considered to have eosinophilic inflammation if they had a blood eosinophil count of at least $150 / \mu \mathrm{L}$ at screening or $300 / \mu \mathrm{L}$ during the previous year. Patients who received mepolizumab, either IV or SC, had a significant reduction in asthma exacerbations and had improved asthma control. These findings are consistent with the results of the Steroid Reduction with Mepolizumab Study (SIRIUS) study. ${ }^{34}$ This randomized, double-blind, placebo-controlled trial explored the steroid sparing effect of $100 \mathrm{mg}$ of SC mepolizumab in asthmatics receiving oral corticosteroids for at least 6 months (mean of $12.5 \mathrm{mg}$ of prednisone/day). All the patients enrolled $(\mathrm{n}=135)$ had evidence of eosinophilic inflammation (similar criteria to the MENSA study) and had an age range of 16-74 years. In addition to improved asthma exacerbation rates and symptoms, patients who were treated with mepolizumab had a significant reduction in corticosteroid requirements compared to placebo. In both the MENSA and SIRUS studies, patients tolerated mepolizumab well and had a similar safety profile compared to placebo. ${ }^{33,34}$ Based on the available evidence, in November 2015 the FDA approved mepolizumab for the treatment of severe asthma with an eosinophilic phenotype (blood eosinophil count of at least $150 / \mu \mathrm{L}$ at the start of treatment or $300 / \mu \mathrm{L}$ in the past 12 months) in patients aged $\geq 12$ years. The recommended dose is $100 \mathrm{mg}$ SC every 4 weeks.

\section{Benralizumab}

More recently, benralizumab, a fully human afucosylated monoclonal antibody to the $\alpha$ subunit of the IL-5 receptor that blocks the effects of IL-5, is under investigation for the treatment of asthma. ${ }^{35,36}$ Preliminary studies in humans showed an adequate safety profile with a significant reduction in eosinophil counts in the blood. ${ }^{37} \mathrm{~A}$ Phase $2 \mathrm{~b}$ dose-ranging study was done to evaluate the effects of benralizumab in 609 uncontrolled asthmatics with and without evidence of eosinophilic inflammation. ${ }^{38}$ At a dose of $100 \mathrm{mg}$ SC (dosing was administered at weeks 1, 4, 8, 16, 26, 32, and 40), patients with eosinophilia had a significant reduction in the rates of exacerbations compared to placebo. Benralizumab was tolerated well at all doses with an adequate safety profile. Although these findings are promising, ongoing Phase 3 studies will further elucidate the safety and efficacy of this anti-IL-5 therapy for the treatment of eosinophilic asthma.

\section{How to select between mepolizumab and reslizumab?}

To date, there are no head-to-head trials comparing the efficacy of mepolizumab and reslizumab. Both the inhibitors of IL-5 have shown, in patients with severe eosinophilic asthma, reductions in exacerbation rates and improvement in quality of life from asthma, and pulmonary function. ${ }^{26,27,33,34}$ Nevertheless, there are some notable differences to consider before selecting therapy. The age of the patient may impact which therapy to administer; mepolizumab is approved for patients aged $\geq 12$ years, while reslizumab is recommended for ages $\geq 18$ years. Dosing and mode of delivery may also influence the choice of therapy. Mepolizumab is administered SC, while reslizumab requires an IV infusion using weight-base dosing. Some patients and clinicians may prefer the more convenient SC dosing. Additionally, patients with obesity may require larger doses of reslizumab, which may impact the cost of therapy. Finally, the cutoffs of blood eosinophils were different between the mepolizumab and reslizumab pivotal trials. Mepolizumab utilized a cutoff of $\geq 150$ eosinophils/ $\mu \mathrm{L}$ to define the eosinophilic phenotype, while the reslizumab trials had a cutoff of $\geq 400$ eosinophils $/ \mu \mathrm{L}$. Therefore, before selecting an anti-IL-5 therapy, careful consideration of all these characteristics is required.

\section{Future directions}

Ongoing trials continue to explore the applications of reslizumab in severe asthma. A Phase 3 trial will investigate the use of reslizumab as a steroid sparing medication in severe asthma (NCT02501629). ${ }^{39}$ Another Phase 3 trial will explore the efficacy of reslizumab using a fixed dose in patients with eosinophilic asthma (NCT02452190). ${ }^{40}$ Notably, in both of these studies, SC dosing will be used to assess this alternative dosing route. SC may be better tolerated, more convenient, and may potentially reduce complications. Future surveillance and "real-life" studies will be needed to further confirm the efficacy and safety of reslizumab in the treatment of the eosinophilic asthma phenotype.

Many questions remain about how anti-IL-5 agents will fit into clinical practice. In those with severe asthma, uncontrolled on moderate-to-high-dose inhaled steroids and at least 1-second controller with evidence of eosinophilic inflammation and sensitization to perennial allergens, omalizumab will likely remain initial treatment of choice in light of longer term experience and safety data compared to antiIL-5 agents. However, in a subset of patients who meet the criteria for omalizumab treatment that either do not respond to treatment or have an incomplete response, anti-IL-5 may be a welcomed option. Head-to-head studies of omalizumab 
and anti-IL-5 treatments would be needed to assess relative efficacy and safety as first-line agents for patients with asthma not controlled with standard treatments, perennial allergen sensitivity, and eosinophilia who would be potentially eligible for both the treatments. In our assessment, current data likely favor anti-IL-5 treatments as a steroid-sparing treatment in patients with oral corticosteroid-dependent asthma with eosinophilia with or without allergen sensitization. Whether anti-IL-5 treatments should be considered in those with long-term steroid dependence in whom it may be difficult to demonstrate peripheral eosinophilia levels associated with a response to drug remains to be determined. Additionally, there is no clear recommendation regarding continuation of therapy and what are the criteria to suspend therapy. These important questions will require prospective, parallel group studies to determine the lasting effects of therapy and consequences of withdrawal. Finally, anti-IL-5 treatments are currently under evaluation for chronic rhinosinusitis with or without nasal polyposis and aspirin-exacerbated respiratory disease, conditions that are important comorbidities impacting asthma, and where eosinophilic airway inflammation plays a prominent role. ${ }^{41,42}$

\section{Conclusion}

Because a significant proportion of patients with asthma remain uncontrolled despite high-dose ICS and long-acting $\beta$-agonists, targeted biological therapies continue to play a role in the armamentarium for asthma therapy. Reslizumab, by neutralizing IL-5, has been shown to safely and effectively treat severe eosinophilic asthma. As data continue to emerge, not only on anti-IL-5 therapies but also on other antibodies that target cytokines that confirm the TH2-driven inflammation, biomarkers will have a major role in patient selection algorithms. Blood eosinophil counts have been shown to adequately select asthmatics that would benefit from reslizumab and other IL-5 neutralizing treatments. Nevertheless, it is important to consider that this therapy remains costly and is not widely available. Additionally, before a patient is considered for this type of treatment, a careful evaluation focusing on an accurate diagnosis, asthma education, trigger avoidance, inhaler compliance, and other key components of asthma care should be performed. Future surveillance and "real-life" studies are still warranted to explore the applications of reslizumab for the treatment of severe asthma. Many questions remain regarding where anti-IL-5 therapy will fit in algorithms for treatments of severe asthma in a variety of different clinical circumstances and in relation to other advanced therapies. In Figure 1, we provide a guideline of how to approach the treatment of severe asthma that has been nonresponsive to standard therapies utilizing treatable traits to select therapy. ${ }^{26,27,33,34,43,44}$ There are no head-to-head trials

Severe asthma

Frequent exacerbations/continuous symptoms despite standard therapies

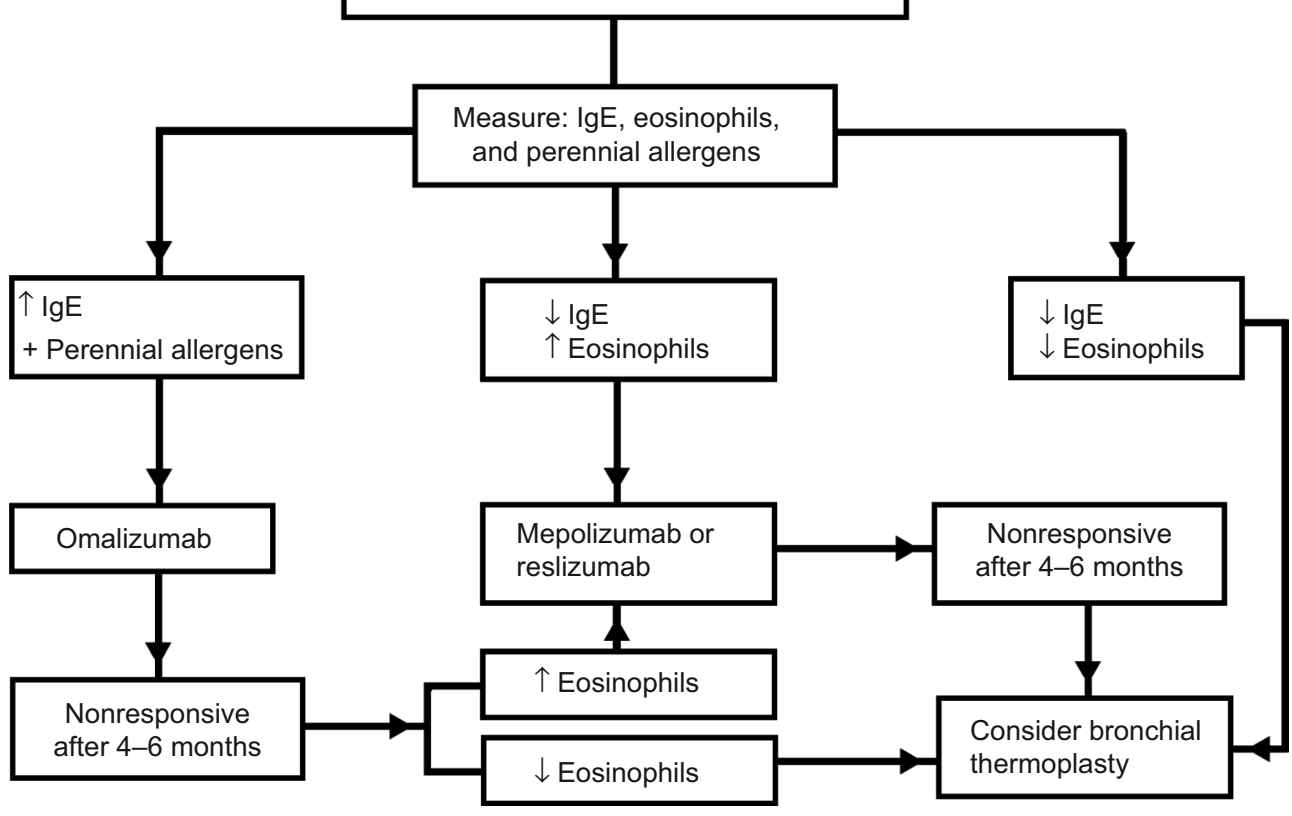

Figure I Suggested approach to the treatment of severe asthma beyond standard therapies. Abbreviation: IgE, immunoglobulin $\mathrm{E}$. 
comparing therapies for severe asthma, so this algorithm should be used only as guide when considering stepping up the therapy for asthma after a careful case-by-case evaluation of the patient considering phenotypical features and a thorough discussion on the risks and benefits of these treatments. Regardless, it is an exciting time for both clinicians and patients as increased options for these difficult-to-treat patients are becoming available.

\section{Disclosure}

The authors report no conflicts of interest in this work.

\section{References}

1. Humbert M, Busse W, Hanania NA, et al. Omalizumab in asthma: an update on recent developments. J Allergy Clin Immunol Pract. 2014;2(5):525-536.

2. Corrigan CJ, Kay AB. T cells and eosinophils in the pathogenesis of asthma. Immunol Today. 1992;13(12):501-507.

3. WellerPF. The immunobiology of eosinophils. NEnglJMed.1991;324(16): 1110-1118.

4. Busse WW, Lemanske RF Jr. Asthma. N Engl J Med. 2001;344(5): 350-362.

5. Peters-Golden M, Henderson WR Jr. Leukotrienes. $N$ Engl J Med. 2007;357(18):1841-1854.

6. Johansson MW. Activation states of blood eosinophils in asthma. Clin Exp Allergy. 2014;44(4):482-498.

7. Walker C, Checkel J, Cammisuli S, Leibson PJ, Gleich GJ. IL-5 production by NK cells contributes to eosinophil infiltration in a mouse model of allergic inflammation. J Immunol. 1998;161(4):1962-1969.

8. Nussbaum JC, Van Dyken SJ, von Moltke J, et al. Type 2 innate lymphoid cells control eosinophil homeostasis. Nature. 2013;502(7470): 245-248.

9. Hogan MB, Piktel D, Landreth KS. IL-5 production by bone marrow stromal cells: implications for eosinophilia associated with asthma. J Allergy Clin Immunol. 2000;106(2):329-336.

10. Lampinen M, Carlson M, Håkansson LD, Venge P. Cytokine-regulated accumulation of eosinophils in inflammatory disease. Allergy. 2004;59(8):793-805.

11. Springer TA. Traffic signals for lymphocyte recirculation and leukocyte emigration: the multistep paradigm. Cell. 1994;76(2):301-314.

12. Hynes RO. Integrins: bidirectional, allosteric signaling machines. Cell. 2002;110(6):673-687.

13. Johansson MW, Kelly EA, Busse WW, Jarjour NN, Mosher DF. Up-regulation and activation of eosinophil integrins in blood and airway after segmental lung antigen challenge. J Immunol. 2008;180(11):7622-7635.

14. Johansson MW, Gunderson KA, Kelly EA, et al. Anti-IL-5 attenuates activation and surface density of $\beta(2)$-integrins on circulating eosinophils after segmental antigen challenge. Clin Exp Allergy. 2013;43(3):292-303.

15. van Rijt L, von Richthofen H, van Ree R. Type 2 innate lymphoid cells: at the cross-roads in allergic asthma. Semin Immunopathol. 2016; 38(4):483-496.

16. Klein Wolterink RG, Kleinjan A, van Nimwegen M, et al. Pulmonary innate lymphoid cells are major producers of IL-5 and IL-13 in murine models of allergic asthma. Eur J Immunol. 2012;42(5):1106-1116.

17. Egan RW, Athwahl D, Chou CC, et al. Inhibition of pulmonary eosinophilia and hyperreactivity by antibodies to interleukin-5. Int Arch Allergy Immunol. 1995;107(1-3):321-322.

18. Zhang J, Kuvelkar R, Murgolo NJ, et al. Mapping and characterization of the epitope(s) of Sch 55700, a humanized mAb, that inhibits human IL-5. Int Immunol. 1999;11(12):1935-1944.
19. Egan RW, Athwahl D, Chou CC, et al. Pulmonary biology of antiinterleukin 5 antibodies. Mem Inst Oswaldo Cruz. 1997;92(Suppl 2): 69-73.

20. Egan RW, Athwal D, Bodmer MW, et al. Effect of Sch 55700, a humanized monoclonal antibody to human interleukin-5, on eosinophilic responses and bronchial hyperreactivity. Arzneimittelforschung. 1999;49(9):779-790.

21. Kips JC, O'Connor BJ, Langley SJ, et al. Effect of SCH55700, a humanized anti-human interleukin-5 antibody, in severe persistent asthma: a pilot study. Am J Respir Crit Care Med. 2003;167(12):1655-1659.

22. Castro M, Mathur S, Hargreave F, et al. Reslizumab for poorly controlled, eosinophilic asthma: a randomized, placebo-controlled study. Am J Respir Crit Care Med. 2011;184(10):1125-1132.

23. Pin I, Gibson PG, Kolendowicz R, et al. Use of induced sputum cell counts to investigate airway inflammation in asthma. Thorax. 1992;47(1):25-29.

24. Peters SP. Counterpoint: is measuring sputum eosinophils useful in the management of severe asthma? No, not for the vast majority of patients. Chest. 2011;139(6):1273-1275; discussion 1275-1278.

25. Rothenberg ME. Eosinophilia. N Engl JMed. 1998;338(22):1592-1600.

26. Castro M, Zangrilli J, Wechsler ME, et al. Reslizumab for inadequately controlled asthma with elevated blood eosinophil counts: results from two multicentre, parallel, double-blind, randomised, placebo-controlled, phase 3 trials. Lancet Respir Med. 2015;3(5):355-366.

27. Corren J, Weinstein S, Janka L, Zangrilli J, Garin M. Phase 3 study of reslizumab in patients with poorly controlled asthma: effects across a broad range of eosinophil counts. Chest. Epub 2016 Mar 24.

28. Bjermer L, Lemiere C, Maspero J, Weiss S, Zangrilli J, Germinaro M. Reslizumab for inadequately controlled asthma with elevated blood eosinophil level: a randomized phase 3 study. Chest. Epub 2016 Apr 4.

29. Klion AD, Law MA, Noel P, Kim YJ, Haverty TP, Nutman TB. Safety and efficacy of the monoclonal anti-interleukin-5 antibody SCH55700 in the treatment of patients with hypereosinophilic syndrome. Blood. 2004;103(8):2939-2941.

30. Hart TK, Cook RM, Zia-Amirhosseini P, et al. Preclinical efficacy and safety of mepolizumab (SB-240563), a humanized monoclonal antibody to IL-5, in cynomolgus monkeys. J Allergy Clin Immunol. 2001;108(2):250-257.

31. Menzies-Gow A, Flood-Page P, Sehmi R, et al. Anti-IL-5 (mepolizumab) therapy induces bone marrow eosinophil maturational arrest and decreases eosinophil progenitors in the bronchial mucosa of atopic asthmatics. J Allergy Clin Immunol. 2003;111(4):714-719.

32. Liu Y, Zhang S, Li DW, Jiang SJ. Efficacy of anti-interleukin-5 therapy with mepolizumab in patients with asthma: a meta-analysis of randomized placebo-controlled trials. PLoS One. 2013;8(3):e59872.

33. Ortega HG, Liu MC, Pavord ID, et al. Mepolizumab treatment in patients with severe eosinophilic asthma. NEngl J Med. 2014;371(13): 1198-1207.

34. Bel EH, Wenzel SE, Thompson PJ, et al. Oral glucocorticoid-sparing effect of mepolizumab in eosinophilic asthma. N Engl J Med. 2014;371(13): 1189-1197.

35. Koike M, Nakamura K, Furuya A, et al. Establishment of humanized anti-interleukin-5 receptor alpha chain monoclonal antibodies having a potent neutralizing activity. Hum Antibodies. 2009;18(1-2):17-27.

36. Kolbeck R, Kozhich A, Koike M, et al. MEDI-563, a humanized anti-IL-5 receptor alpha mAb with enhanced antibody-dependent cell-mediated cytotoxicity function. J Allergy Clin Immunol. 2010; 125(6):1344-1353.

37. Busse WW, Katial R, Gossage D, et al. Safety profile, pharmacokinetics, and biologic activity of MEDI-563, an anti-IL-5 receptor alpha antibody, in a phase I study of subjects with mild asthma. J Allergy Clin Immunol. 2010;125(6):1237-1244.

38. Castro M, Wenzel SE, Bleecker ER, et al. Benralizumab, an antiinterleukin 5 receptor $\alpha$ monoclonal antibody, versus placebo for uncontrolled eosinophilic asthma: a phase $2 \mathrm{~b}$ randomised dose-ranging study. Lancet Respir Med. 2014;2(11):879-890. 
39. Teva Branded Pharmaceutical Products, R\&D Inc. An efficacy and safety study of reslizumab subcutaneous in patients with oral corticosteroid dependent asthma and elevated blood eosinophils. Available from: https://clinicaltrials.gov/ct2/show/NCT02501629?term=NCT0 2501629\&rank=1. NLM identifier: NCT02501629. Accessed May 1, 2016.

40. Teva Branded Pharmaceutical Products, R\&D Inc. Study of reslizumab in patients with uncontrolled asthma and elevated blood eosinophils. Available from: https:/clinicaltrials.gov/ct2/show/NCT02452190?term $=$ NCT02452190\&rank=1. NLM identifier: NCT02452190. Accessed May 1, 2016.
41. Gevaert P, Lang-Loidolt D, Lackner A, et al. Nasal IL-5 levels determine the response to anti-IL-5 treatment in patients with nasal polyps. J Allergy Clin Immunol. 2006;118(5):1133-1141.

42. Gevaert P, Van Bruaene N, Cattaert T, et al. Mepolizumab, a humanized anti-IL-5 mAb, as a treatment option for severe nasal polyposis. J Allergy Clin Immunol. 2011;128(5):989-995.

43. Humbert M, Busse W, Hanania NA, et al. Omalizumab in asthma: an update on recent developments. J Allergy Clin Immunol Pract. 2014;2(5):525-536.

44. Castro M, RubinAS, Laviolette M, etal. Effectiveness and safety of bronchial thermoplasty in the treatment of severe asthma: a multicenter, randomized, double-blind, sham-controlled clinical trial. Am J Respir Crit Care Med.2010;181(2):116-124.

\section{Publish your work in this journal}

The Journal of Asthma and Allergy is an international, peer-reviewed open access journal publishing original research, reports, editorials and commentaries on the following topics: Asthma; Pulmonary physiology; Asthma related clinical health; Clinical immunology and the immunological basis of disease; Pharmacological interventions and new therapies. This journal is included in PubMed. The manuscript management system is completely online and includes a very quick and fair peer-review system, which is all easy to use. Visit http://www dovepress.com/testimonials.php to read real quotes from published authors. 